\title{
Revista Colombiana de

\section{Página web de la REVISTA COLOMBIANA DE CARDIOLOGía: camino a la modernización}

\author{
Website of the COLOMBIAN JOURNAL OF CARDIOLOGY: Path to modernization
}

\section{Comité página web Revista Colombiana de Cardiología}

Recibido el 13 de julio de 2015; aceptado el 14 de julio de 2015

Evidencias históricas demuestran que la transferencia del conocimiento se ha edificado sobre la transmisión oral, la escritura, la pintura, la música, el cine, la radio y la televisión.

La evolución del conocimiento ante un universo tecnológico que se abre paso en la sociedad de nuestros tiempos, hace que la Internet, la intranet y las redes sociales desempeñen un papel preponderante en toda organización en vía de desarrollo.

Estamos viviendo una revolución, que lejos de ser una moda pasajera es fruto de fuerzas incontrolables e irreversibles: la globalización, la informática y la desintermediación económica. En un mundo globalizado y en continua evolución se observa cómo las tecnologías avanzan, las herramientas que generan información rápida y eficiente como sistemas operativos, software de aplicación y programas en general evolucionan de manera vertiginosa, se actualizan o simplemente mejoran, y se genera así una necesidad de conocimiento y de renovación rápida.

Debido a la importancia del conocimiento científico como activo primordial de la Sociedad Colombiana de Cardiología y Cirugía Cardiovascular, la gestión de este a través de la REVISTA COLOMBIANA DE CARDIOLOGía representa una prioridad dentro de la estructura organizacional. La transferencia del conocimiento científico relacionado con la profesión médica es nuestra labor principal y para lograrlo se han requerido grandes esfuerzos para adaptarnos y administrar los servicios en una nueva plataforma, para la que se han desarrollado y revisado contenidos científicos a través de formatos web, aplicaciones y otros sistemas, ajustándonos a servidores de almacenamiento y control de datos científicos, entre otros.

De otra parte, la indexación internacional de publicaciones seriadas se ha convertido en la ventana más grande de visibilidad del conocimiento, siendo este un instrumento importante para los investigadores, ya que permite una clasificación integrada de las revistas científicas con base en parámetros de calidad. Los procesos de indexación durante los últimos años han transformado, de una forma u otra, el contexto de las publicaciones científicas. Los autores envían sus artículos de acuerdo con la notoriedad de cada revista, de modo que estas se hacen visibles a través de la referenciación.

Por tal razón, durante el último año, en el interior de la Revista se ha venido trabajando en beneficio de un gran cambio en el diseño y contenido de la página web, con el cual se busca generar un espacio de información y actualización científica en el que todos los números de la publicación estén disponibles y exista, ante todo, transferencia de conocimiento a la comunidad médica, de enfermería y a las profesiones afines con la cardiología y la cirugía cardiovascular. En el desarrollo de la página web se plantea una fuerte sinergia entre la disponibilidad de la información, el proceso de transferencia del conocimiento, el capital intelectual, la estructura tecnológica, la disponibilidad de 
herramientas, entre otros, en procura de mantener la independencia científica, la ética, el estilo de dirección, el liderazgo, la estructura organizativa, la estrategia empresarial, los recursos humanos y económicos, y la gestión de los sistemas de información y comunicación, etc. Gracias a la plataforma digital de la Revista en Elsevier, se han tenido grandes avances, visibilidad internacional, la posibilidad de leer los artículos en línea desde cualquier dispositivo móvil y obtener el reporte de estadísticas mes a mes en lo concerniente al comportamiento de la página.

Es así como, gracias a fuentes como Google Analytics y EES Elsevier System, y a todo el esfuerzo hecho por el grupo de trabajo de la Revista, se ha cuadriplicado el número de visitas por mes en el último año, reportándose a junio de 2015, 3.498 visitas a la página (fig. 1), procedentes de Colombia $(50,4 \%)$ y el resto de Latinoamérica, EE. UU., Rusia, Europa, Canadá, Asia, Australia y algunos países de África (fig. 2). El perfil de usuarios es del 54,2\% para el género masculino y el $76,5 \%$ se encuentran en edades entre los 18 a 44 años. Ha habido, asimismo, un crecimiento exponencial de descargas de pdf, que rápidamente superaron nuestros objetivos y llegaron a 5.722 descargas/mes. Existe un número mayor de seguidores en redes sociales, con índice de cero comentarios negativos. El factor de impacto es 0,1163 ; 0,1111; y 3,792 para la Revista Colombiana de Cardiología, la Revista Chilena de Cardiología y la Revista Española de Cardiología, respectivamente, cifras que reflejan la buena situación de nuestra Revista en Latinoamérica,

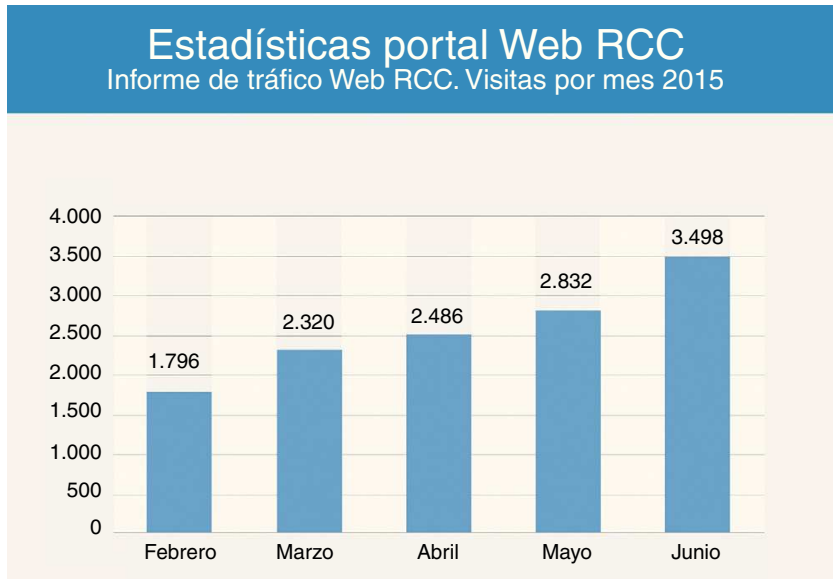

Figura 1 Tomada de Google Analytics.

y a la vez alientan al gran reto de mejorar y posicionarla en el segundo lugar en lengua castellana a mediano plazo.

Evaluar los logros obtenidos es la contrapartida del desarrollo y actualización de la página web en función de las exigencias de la vida real. Dado su carácter intangible se tienen estos indicadores relacionados con el funcionamiento organizacional, así como con el impacto de los servicios y productos de la Revista.

\section{Visitas portal Web RCC Junio 2015}

\begin{tabular}{|c|c|c|c|}
\hline \multirow{2}{*}{ Country } & \multicolumn{3}{|l|}{ Acquisition } \\
\hline & sessions & $\begin{array}{c}\% \text { new } \\
\text { Sessions }\end{array}$ & New users \\
\hline & $\begin{array}{r}3,498 \\
\% \text { of total: } \\
100.00 \% \\
(3,498)\end{array}$ & $\begin{array}{r}82.48 \% \\
\text { Avg for view: } \\
82.36 \% \\
(0.14 \%)\end{array}$ & $\begin{array}{r}2,885 \\
\% \text { of total: } \\
100.14 \% \\
(2,881)\end{array}$ \\
\hline 1. Colombia & $1,763(50.40 \%)$ & $70.11 \%$ & $1,236(42.84 \%)$ \\
\hline $\begin{array}{l}\text { 2. United } \\
\text { States }\end{array}$ & $611(17.47 \%)$ & $97.22 \%$ & $594(20.59 \%)$ \\
\hline 3. Russia & $427(12.21 \%)$ & $97.42 \%$ & $416(14.42 \%)$ \\
\hline 4. (not set) & $124(3.54 \%)$ & $100.00 \%$ & $124(4.30 \%)$ \\
\hline 5. Spain & $63(1.80 \%)$ & $87.30 \%$ & $55(1.91 \%)$ \\
\hline 6. Mexico & $54(1.54 \%)$ & $92.59 \%$ & $50(1.73 \%)$ \\
\hline 7. Brazil & $51(1.46 \%)$ & $84.31 \%$ & $43(1.49 \%)$ \\
\hline 8. Peru & $44(1.26 \%)$ & $81.82 \%$ & $36(1.25 \%)$ \\
\hline 9. Argentina & $38(1.09 \%)$ & $92.11 \%$ & $35(1.21 \%)$ \\
\hline 10. Venezuela & 38 (1.09\%) & $89.47 \%$ & $34(1.18 \%)$ \\
\hline
\end{tabular}

Figura 2 Tomada de Google Analytics. 
Retomando el nuevo diseño de la página web se incluyen secciones exclusivas, como archivos de todos los números de la Revista en donde se puede consultar no solo en formato pdf sino en línea, y otras en las que se puede hallar información acerca de los criterios de uniformidad para el envío de manuscritos, así como detalles de la Revista (comités, quiénes somos), eventos científicos relevantes, cómo hacer donaciones, cómo pautar, noticias relacionadas con las principales publicaciones en revistas indexadas, forma de contacto, redes sociales y entrevistas con líderes de opinión. Se está desarrollando, asimismo, un espacio a manera de «micrositio» con la industria (AstraZeneca, Terumo, Aspen y Abbott Vascular, y próximamente otros) para generar gran cantidad de información permanente y actualizada en lo que respecta a síndromes coronarios agudos, intervención coronaria compleja por vía transradial, terapia antitrombótica, uso de nuevas tecnologías como dispositivos endovasculares biorreabsorbibles y tratamiento de enfermedades estructurales del corazón.
De otro lado, redes sociales como Facebook, Twitter, Instagram, Youtube, sociedades cibernéticas de las que hoy en día todos formamos parte, no solo sirven para publicar fotos y perfiles personales sino de empresas, y en todo caso, son un escaparate al mundo para exhibir lo mejor. Suponen un contacto ilimitado y a tiempo real, que se consigue gracias a la interactividad, uno de sus rasgos más distintivos y novedosos. Antes de las redes sociales, las empresas y los medios no tenían formas de comunicarse con el público y así conocer su opinión. Hoy en día, en virtud de estas redes, es posible establecer un contacto mutuo entre los gestores del conocimiento (autores), los transmisores del conocimiento y los lectores. Ahora mismo, un artículo dispuesto en la revista digital no se considera terminado hasta que los receptores han añadido sus reflexiones al original.

En general y para finalizar, con la nueva página web se espera generar mayor interés, motivación y participación de la comunidad médica. Así, pues, quedamos atentos a las sugerencias y observaciones que deseen manifestar. 